\title{
La huerta es un tesoro si quien la labra es moro: el Ecomuseo del Río Caicena (Almedinilla, Córdoba)
}

\begin{abstract}
Las huertas que rodean pueblos y ciudades han sido históricamente territorios de minifundios campesinos orientados a abastecer los mercados locales de frutas y verduras frescas de temporada. En estos espacios se generó un patrimonio agrario que a raíz de la industrialización está amenazado y que, en el contexto actual, cobra sentido recuperar y actualizar. El Ecomuseo del Río Caicena es un proyecto municipal inscrito en la llamada nueva museología, que tiene como hilo conductor al río y lo que encuentra en su transcurrir: un territorio rural y agrícola que aún mantiene su identidad.
\end{abstract}

Ignacio Muñiz | director del Ecomuseo del Río Caicena-Museo Histórico de Almedinilla

Álvaro Gaspar | máster de agroecología, Universidad Internacional de Andalucía

Marta Soler | Dpto. Economía Aplicada II, Universidad de Sevilla

David Gallar | Dpto. CC. Sociales y Humanidades, Universidad de Córdoba

URL de la contribución <www.iaph.es/revistaph/index.php/revistaph/article/view/3755>

\section{El Ecomuseo del Río Caicena y sus huertas tradicionales}

El proyecto, que conjuga territorio, patrimonio interrelacionado y participación ciudadana, nació en 1994 con un inventario de recursos, diagnóstico de los mismos y planes parciales de actuación, después de una lucha vecinal (encauzada a través de la Asociación Amigos de Waska) para conservar y proteger los importantes yacimientos arqueológicos (motores del resto del proyecto) abandonados a su suerte tras su excavación parcial en 1989 por el Seminario de Arqueología de la Universidad de Córdoba. Con actividades de denuncia, concienciación, formación y difusión, el proyecto se fue concretando a partir de 1998

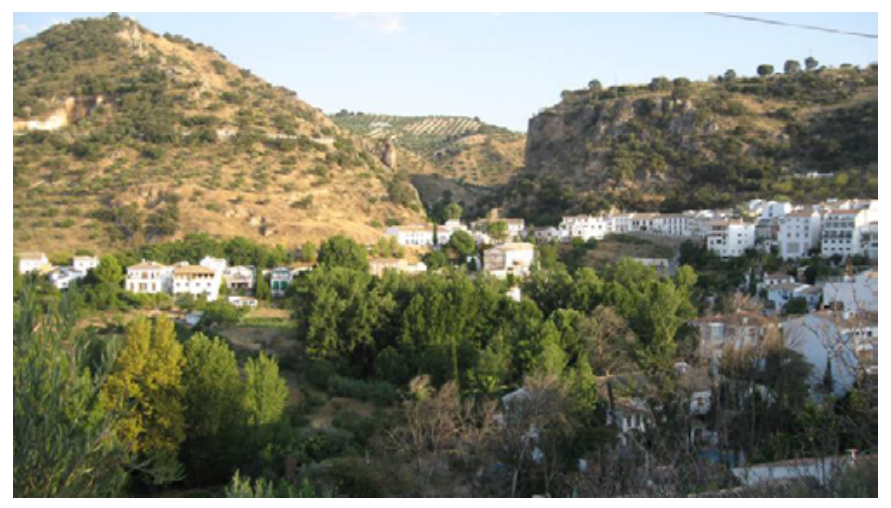

Huertas tradicionales de Almedinilla | foto Museo Histórico de Almedinilla (Córdoba), titular de todas las imágenes de la contribución en diferentes núcleos museísticos y propuestas: Museo Histórico (con sus salas dedicadas al olivar, la cultura ibérica y la romana); Sala de los Molinos y Cereales; Aula del Campesinado; Centro de Exposiciones Temporales; poblado ibérico del Cerro de la Cruz; villa romana de El Ruedo; alojamiento para investigadores; taller de restauración y almacén; sala de conferencias y talleres; rutas senderistas; propuestas formativas y lúdicas... así como la recuperación de tradiciones, saberes y valores inmateriales de un mundo rural frágil, cambiante y en peligro (MUÑIZ JAÉN, 2008).

En el Ecomuseo, desde el compromiso con el mundo rural y desde el mundo rural, partimos del estudio de la Historia (y su reflejo en el patrimonio histórico y natural conservado) siendo conscientes del proceso histórico seguido en Andalucía, lleno de dependencias económicas y políticas (ACOSTA SÁNCHEZ, 1978).

De ahí que las transformaciones principales en el mundo rural andaluz que nos preocupan vienen de la culminación de un proceso de descampesinización obligado por la adaptación a los mercados globales (iniciado en el siglo XIX) que conlleva desde entonces la paulatina pérdida de los mercados locales, la desaparición del pequeño y mediano productor con sus explotaciones heterogéneas y autosuficientes, el abandono de los pro- 
ductos autóctonos y de calidad, y en definitiva la pérdida de la relación estrecha entre el ser humano y la tierra. Esta deriva, del mismo modo, afecta de lleno a una cultura propia andaluza llena de expresiones genuinas que van cediendo ante una homogenización cultural que empobrece las respuestas culturales locales.

Sabedores también de los ciclos intermitentes (pero continuos) de luchas y resistencias campesinas a esta inercia, el proyecto de ecomuseo imprime una visión crítica del pasado que nos lleva a un análisis transformador del presente, pretendiendo frenar y denunciar los efectos de una economía y una sociedad que quiere convertir todo en mercancía: el patrimonio histórico, el entorno natural, los valores comunitarios, el agua, los alimentos, el aire, el sol... la propia salud.

Desde el Ecomuseo del Río Caicena, por tanto, adoptamos un papel de resistencia, que, como nos dice Isidoro Moreno, en la cultura campesina andaluza se expresa en el valor dado a las relaciones humanas, la diferenciación entre el ser y el tener, la negativa a interiorizar simbólicamente la inferioridad colectiva e individual en el plano político y económico, y el relativismo ideológico en las creencias, siempre que no afecten a la autoestima (MORENO NAVARRO, 2002). Resistencias a las que se unen ahora otras, también globales, que pretenden conectar las luchas del campesinado desde una visión de la tierra sustentada en cambios en el modelo económico, social y político (causante de la reproducción de la concentración agraria) incorporando una cosmovisión simbólica y material del territorio y sus recursos y recuperando la propiedad social de la tierra.

Partiendo de esta base se protegieron en el Plan General de Ordenación Urbana de Almedinilla las zonas de huertas tradicionales (convertidas en otros lugares en espacios residenciales o en polígonos industriales), nos integramos en la Red de Centros de Interpretación Etnológica (Red CIE) con este propósito, y a través de las actividades de investigación, montajes museográficos, actividades de dinamización, jornadas y encuentros proseguimos en esta labor que hoy continúa con la reciente firma de un convenio de colaboración con el Instituto de Sociología y Estudios Campesinos (ISEC) de la Universidad de Córdoba para elaborar estrategias y estudios como el que presentamos aquí.

\section{Del abandono a la recuperación de las huertas históricas}

Como decimos, las huertas, tradicionalmente un minifundio familiar campesino orientado al abastecimiento alimentario de los mercados de proximidad, han ido abandonándose presionadas por la industrialización. El despegue urbano-industrial atrajo a las y los jornaleros sin tierra que perdieron la lucha por la reforma agraria en la guerra civil y que buscaban mejoras salariales y estabilidad laboral. Le siguieron las familias campesinas que cultivaban pequeñas fincas al caer los precios agrarios a medida que el productivismo avanzaba y generaba una crisis de sobreproducción. La mecanización, el uso de semillas comerciales híbridas y de agroquímicos generó una nueva agricultura desvinculada de la naturaleza y de costes de producción crecientes que resultaba atractiva para las grandes fincas en las que el principal coste era el trabajo asalariado (NAREDO PÉREZ, 2004).

Estos cambios fueron reforzados por la desconexión de la dieta de la estacionalidad de los alimentos frescos de temporada frente a una alimentación basada en la proteína animal y los alimentos procesados. Esta dieta urbano-industrial, convertida en signo de distinción, es además adquirida en supermercados e hipermercados abastecidos en masa por los mercados agroalimentarios globales, abandonando los mercados de abastos y el comercio especializado de barrio (BURCH; LAWRENCE, 2007). Se consolida así una desagrarización cultural y

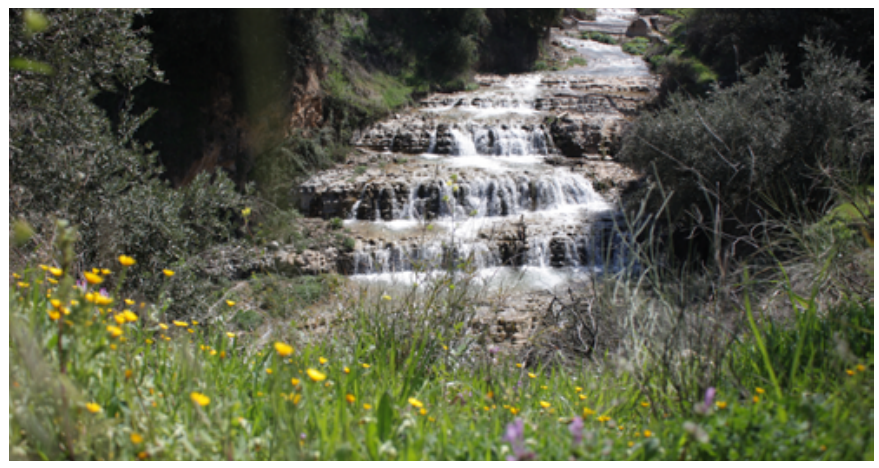

Río Caicena 
material arraigada en el debilitamiento del vínculo local que unía la producción y el consumo alimentario.

Para más abundamiento, en las últimas décadas la aceleración de los procesos de urbanización por la burbuja inmobiliaria ha destruido de forma irreversible importantes zonas de huertas periurbanas (AA.VV., 2006). A ello se ha unido el efecto de la Política Agraria Comunitaria (PAC) que estimula la selección de cultivos para maximizar subvenciones, primando el olivar y los cultivos herbáceos frente a las huertas, además de consolidar la desigualdad económica al repartir el dinero público en función de la producción y la superficie (SOLER MONTIEL, 2007).

De esta manera, en un contexto de crisis global como el actual, donde a la debacle social y económica se le une el deterioro ecológico, recuperar las huertas periurbanas abandonadas cobra un nuevo sentido. Si las técnicas de cultivo son agroecológicas, es decir, basadas en los conocimientos tradicionales campesinos para el manejo de la biodiversidad, se contribuye simultáneamente a la mejora medioambiental y a la economía campesina con una agricultura de bajos costes en insumos (GLIESSMAN, 2007). Porque la agroecología propone no sólo un cambio de manejo agrario sino el impulso a nuevos sistemas agroalimentarios locales a partir de la rearticulación en proximidad del vínculo producción-consumo alimentario en un contexto de cohesión y equidad socioeconómica (SEVILLA GUZMÁN, 2006).

Que lo que comemos sea producido cerca por gente conocida y que el reparto de dinero que se moviliza para alimentarnos sea lo más transparente y equitativo posible son argumentos sensatos que están impulsando las múltiples iniciativas agroecológicas que se están poniendo en marcha en muy diversos lugares, también en Andalucía (SEVILLA GUZMÁN et ál., 2012; SOLER MONTIEL; CALLE COLLADO, 2010), propuestas que avanzan hacia la soberanía alimentaria como alternativa a la globalización agroalimentaria (SEVILLA GUZMÁN; SOLER MONTIEL, 2010).

Esta estrategia agroecológica de recuperar las huertas históricas se basa por último en la actualización de los saberes y conocimientos tradicionales campesinos. Es pues una estrategia de desarrollo rural sostenible centrada en el patrimonio agrario tanto material como inmaterial.

\section{El papel de la ciudadanía y el apoyo institucional}

La implicación de la ciudadanía en el mantenimiento de un mundo rural vivo es un pilar esencial. Partir de la identidad local, del orgullo local por su propia cultura, es la base para que ese territorio, ese paisaje, esas formas de hacer y de vivir sigan vigentes y con fuerza suficiente para definir el rumbo de su futuro. No se trata de aferrarse a la nostalgia, al romanticismo o al bucolismo, ni de entregarse al desarrollismo de los polígonos industriales o al monocultivo esquilmador, sino que la ciudadanía tenga capacidad de reconocer sus necesidades, proponer estrategias y tomar decisiones para dar respuesta a los problemas y las oportunidades locales.

Aprovechar las iniciativas locales que van en esta dirección es básico y deben apoyarse desde las instituciones locales, promoviendo esos espacios de reflexión vinculados a criterios de sustentabilidad: el cómo construir desde los pueblos alternativas ecológicamente respetuosas, económicamente viables, socialmente justas y culturalmente adaptadas.

En la complementariedad entre el impulso de la ciudadanía y la capacidad de las instituciones para dar apoyo a esas iniciativas y a la vez promover, sin apropiarse de ellos, espacios de participación efectiva, hay un potencial enorme para dar respuesta a las necesidades de la gente de los pueblos desde sus propias capacidades y recursos. Del mismo modo, cualquier apoyo que venga desde otros ámbitos con esa predisposición a facilitar y a acompañar esas dinámicas locales desde criterios de sustentabilidad es una aportación más a la madurez de los procesos locales y a la toma de decisiones apropiadas.

\section{El proyecto de agroecología para Almedinilla}

El proyecto de Almedinilla aúna los esfuerzos del proyecto municipal del Ecomuseo del Río Caicena (y del Ayuntamiento), del Instituto de Sociología y Estudios Campesinos (ISEC)-Universidad de Córdoba (UCO) y de la Universidad de Sevilla (US). 


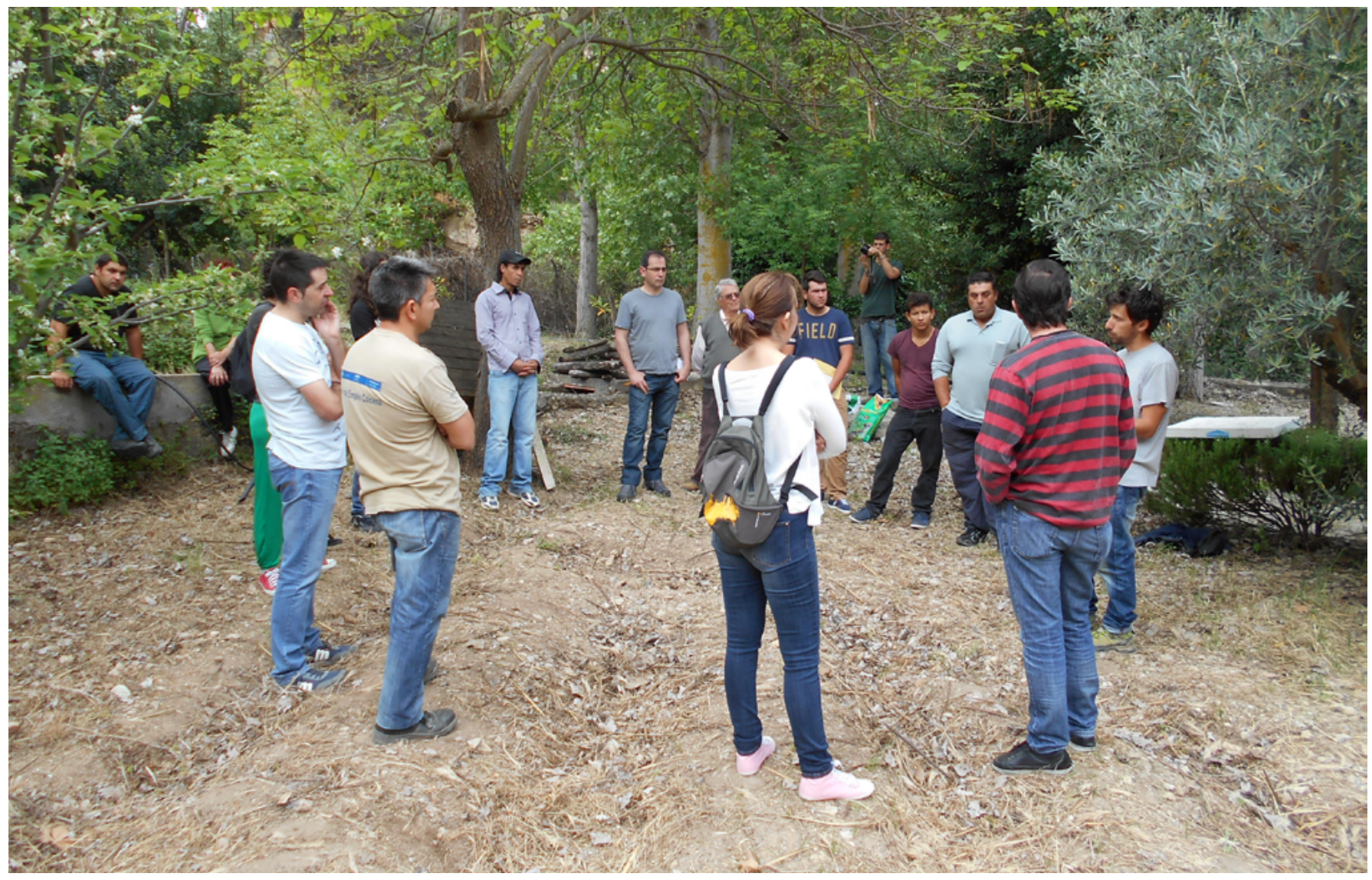

Curso de agroecología

Esta iniciativa agroecológica supone una apuesta a largo plazo por relocalizar el sistema agroalimentario bajo criterios de soberanía alimentaria a través de la recuperación del uso y valor de la vega del río Caicena, de los productos locales y la distribución local (GASPAR, 2015).

Transitar este camino no puede ser sino contando con la población almedinillense, por lo que se ha optado por el uso de las metodologías participativas como la Investigación-Acción Participativa (IAP) la cual entendemos como una metodología de investigación y como un proceso de intervención social simultáneo (BASAGOITI; BRU; LORENZANA, 2001) que permite articular a distintos actores locales, tanto productores, restauradores, minoristas o administraciones públicas, con el objetivo de marcar una hoja de ruta común. De este modo, tal y como proponen López García y Guzmán Casado (2013), este proceso de transición agroecológica se ha centrado en el sector agrario como pieza clave del proceso, pero sin olvidar el resto de actores implicados.

En esta fase inicial se ha trabajado el diagnóstico del municipio desde dos ópticas distintas: el agroecosistema y el sistema agroalimentario, la formación en hortofruticultura y la dinamización y acompañamiento de los distintos sectores a la hora de participar en esta iniciativa municipal.

Los resultados obtenidos de estas primeras fases de trabajo han revelado que en el término municipal existen cinco grandes zonas hortícolas, de las cuales una de ellas se presenta como la óptima: la correspondiente con el margen derecho del río Caicena. Esta zona tiene ventajas claras respecto a las demás, ya que dispone de agua durante todo el año (gracias a la regulación hídrica que ejercen los acuíferos calcáreos aguas arriba), el 
suministro de agua por gravedad (debido a la geomorfología de la zona) y la disposición de una red de acequias que ha sido recientemente restaurada y que se encuentra gestionada por una recién constituida comunidad de regantes.

Es cierto que al observar las zonas de cultivo hortícola se aprecia cómo la presión del monocultivo del olivar, debido a su mayor rentabilidad, está desplazando el cultivo hortofrutícola (llegando a día de hoy a suponer en el municipio la mitad de la superficie de vega) y que las parcelas restantes se encuentran principalmente en situación de abandono o destinadas al consumo familiar, quedando sólo algunas parcelas dedicadas a la producción hortofrutícola de forma semi-profesional. Esta limitada superficie cultivable y los nuevos usos provocan la dificultad de acceso a tierras de forma estable, siendo habituales las cesiones y arriendos informales y por periodos cortos de tiempo.

Por otro lado los conocimientos tradicionales han sufrido un gran retroceso a raíz del abandono de la hortofruticultura como forma de vida (en manos ahora de las personas mayores del pueblo) a excepción de aquellos saberes que por la aceptación y demanda local de los cultivos se han mantenido con los años, destacando en ello la gran diversidad de frutales tanto autóctonos como de variedades foráneas que se conservan salpicados por el municipio.

El sector agrario dedicado a la hortofruticultura está por tanto muy debilitado, quedando apenas una docena de personas dedicadas, ya sea parcial o totalmente, con edades que superan los cuarenta años. Entre ellas encontramos dos personas jóvenes que manejan sus fincas de forma ecológica, una de forma profesional y otra más informal.

A raíz del trabajo realizado de formación y dinamización diversas personas se han interesado por la producción agroecológica de forma profesional, siendo principalmente mujeres, jóvenes y desempleados sin experiencia previa y sin tierra. Esta activación social viene acompañada de la voluntad del Ayuntamiento por promover la agroecología en el municipio, poniendo a disposición de la población personal de acompañamiento, diversos canales de comercialización y la posibilidad de cesión de tierras a partir de la creación de un banco de tierras.

A su vez el proceso de dinamización y acompañamiento ha activado otros sectores como la distribución minorista, la restauración y el consumo social de Almedinilla, lo que ha llevado a iniciar proyectos de fomento del consumo de productos locales, acuerdos con la administración local para el abastecimiento de los centros públicos (colegio, guardería, residencia de ancianos) o la voluntad de minoristas y restauradores por introducir productos locales y agroecológicos en su oferta.

A estas potencialidades hay que sumar la gran aceptación por parte de la población de los productos "del terreno" y la presencia de una potente red de productores y consumidores ecológicos en la comarca de la Subbética cordobesa (donde se ubica Almedinilla): "Subbética ecológica", que ya tiene presencia en el municipio a través de un local de restauración y hotel rural que ofrece sus productos.

De las condiciones preexistentes en el territorio y de la ejecución de esta primera fase podemos apreciar que existen condiciones muy positivas para el éxito de este proyecto. Sin lugar a dudas se están sentando las bases para un proyecto de desarrollo endógeno que permitiría al municipio de Almedinilla reinventarse desde lo local incorporando estas preocupaciones dentro de la dinámica cotidiana del ecomuseo, en donde se contempla la recuperación de elementos etnológicos relacionados con la huerta: acequias, azudes, minas de agua, instrumentales... y otros saberes inmateriales, creación de un banco de tierras, impulso a una asociación de productores-consumidores, recuperación de semillas autóctonas, creación de huertas de recreo, huerto de experimentación, rutas y paquetes turísticos bajo esta modalidad... para lo cual, en este caso concreto, consideramos que el papel del Ayuntamiento de Almedinilla, con independencia de la necesaria iniciativa ciudadana, es fundamental como motor del proyecto. 


\section{NOTAS}

1. Este dicho popular de origen medieval hace alusión a la visión del campesino que cultiva laboriosamente las huertas como persona poseedora de sabiduría y arte que genera riqueza y así "el morisco pasó a simbolizar una mano de obra competente bien preparada y generadora de riquezas" (AMAHJOUR, 2012: 180).

\section{BIBLIOGRAFÍA}

- AA. VV. (2006) Informe Cambios de Ocupación del Suelo en España. OSE, Observatorio de la Sostenibilidad en España. Madrid: Ministerio de Medio Ambiente, Fundación Biodiversidad y Fundación Universidad de Alcalá, 2006

- ACOSTA SÁNCHEZ, J. (1978) Andalucía. Reconstrucción de una identidad y la lucha contra el centralismo. Barcelona: Anagrama, 1978

- AMAHJOUR, A. (2012) Aproximación semiótica a unidades fraseológicas españolas de temática mora y morisca. Paremia, 21, 2012, pp. $177-186$

- BASAGOITI, M.; BRU, P.; LORENZANA, C. (2001) IAP de bolsillo. Madrid: Acsur-Las Segovias, 2001

- BURCH, D.; LAWRENCE, G. A. (2007) Supermarkets and agri-food supply chains: Transformations in the production and consumption of food. Cheltenham, England: Edwards Publishing Ltd, 2007

- GASPAR, A. (2015) Acompañamiento al proceso de transición agroecológica en el municipio de Almedinilla (Córdoba, España). Trabajo final de master inédito, Universidad Internacional de Andalucía

- GLIESSMAN, S. (2007) Agroecology: The ecology of Sustainable Food Systems. Boca Ratón, USA: CRC Press, 2007

- LÓPEZ GARCÍA, D.; GUZMÁN CASADO, G. (2013) Metodologías participativas para la transición agroecológica. Valencia: SEAE, 2013 (Cuadernos técnicos de la Sociedad Española de Agricultura Ecológica, n. ${ }^{\circ} 10$ )

- MORENO NAVARRO, I. (2002) La globalización y Andalucía. Entre el mercado y la identidad. Sevilla: Mergablum, 2002

- MUÑIZ JAÉN, I. (2008) El Ecomuseo del Río Caicena (Almedinilla-Córdoba): un proyecto de desarrollo rural desde el patrimonio histórico-natural ¿y la participación ciudadana? En ARRIETA, I. (ed.) Participación ciudadana, patrimonio cultural y museos. Entre la teoría y la praxis. Bilbao: Universidad del País Vasco, 2008, pp. 95-113

- MUÑIZ JAÉN, I. (2010) Equipamientos culturales: ¿infraestructuras al servicio de la cultural rural? En SOLER MONTIEL, M.; GUERRERO QUINTERO, C. (coord.) Patrimonio cultural en la nueva ruralidad andaluza. Sevilla: Instituto Andaluz de Patrimonio Histórico, 2010, pp. 174-187 (PH Cuadernos, n. ${ }^{\circ} 26$ )

- NAREDO PÉREZ, J. M. (2004) La evolución de la agricultura en España (1940-2000). Granada: Universidad de Granada, 2004

- SEVILLA GUZMÁN, E. (2006) De la Sociología Rural a la Agroecología. Barcelona: Editorial Icaria, 2006

- SEVILLA GUZMÁN, E.; SOLER MONTIEL, M. (2010) Agroecología y soberanía alimentaria: alternativas a la globalización agroalimentaria. En SOLER MONTIEL, M.; GUERRERO QUINTERO, C. (coord.) Patrimonio cultural en la nueva ruralidad andaluza. Sevilla: Instituto Andaluz de Patrimonio Histórico, 2010, pp. 191-217 (PH Cuadernos, n. ${ }^{\circ}$ 26)

- SEVILLA GUZMÁN, E.; SOLER MONTIEL, M.; GALLAR HERNÁNDEZ, D. et ál. (2012) Canales Cortos de Comercialización Alimentaria en Andalucía. Sevilla: Centro de Estudios Andaluces, 2012

- SOLER MONTIEL, M. (2007) OMC, PAC y globalización agroalimentaria. Viento Sur, n. ${ }^{\circ}$ 94, 2007, pp. 37-45

- SOLER MONTIEL, M.; CALLE COLLADO, A. (2010) Rearticulando desde la alimentación: canales cortos de comercialización en Andalucía. En SOLER MONTIEL, M.; GUERRERO QUINTERO, C. (coord.) Patrimonio cultural en la nueva ruralidad andaluza. Sevilla: Instituto Andaluz de Patrimonio Histórico, 2010, pp. 258-283 (PH Cuadernos, n. ${ }^{\circ}$ 26) 